\title{
Análisis de flujos de escombros desde un enfoque dendrocronológico en Ixtacamaxtitlán, Sierra Norte de Puebla, México
}

\author{
Marco Antonio Pablo-Pablo ${ }^{1, *}$, Osvaldo Franco-Ramos ${ }^{2}$, e Irasema Alcántara-Ayala ${ }^{2}$
}

${ }^{1}$ Posgrado en Geografía, Universidad Nacional Autónoma de México, Ciudad Universitaria, 04510, Coyoacán, Ciudad de México, México.

${ }^{2}$ Instituto de Geografía, Universidad Nacional Autónoma de México, Ciudad Universitaria, 04510, Coyoacán, Ciudad de México, México.

*pablopablo.m.a@gmail.com

\section{RESUMEN}

Los procesos de remoción en masa son una de las amenazas geomorfológicas más importantes en México, debido a sus potenciales consecuencias como el desastre ocurrido en octubre de 1999 en las montañas de la Sierra Norte de Puebla, donde cientos de procesos de remoción ocasionaron graves daños a la población. El propósito de este estudio fue la reconstrucción de flujos de escombros en dos valles localizados en el Cerro Tenextepecuaco, dentro de la Sierra Norte de Puebla, con base en métodos geomorfológicos y dendrocronológicos. Se estudiaron 37 árboles de Juniperus deppeana, para elaborar una cronología de referencia local, así como para fechar y mapear los flujos de escombros y determinar la estabilidad del relieve con base en la edad de los árboles. El análisis comparativo de las curvas de lluvia máxima en 24 hrs, para el periodo de mayo a octubre de 1992 a 2013, y el Índice de Ancho de Anillo (IAA) revelaron que en agosto de 2007 y agosto de 2010 se reactivaron dos canales del valle poniente como consecuencia de las intensas lluvias de 93 y $56 \mathrm{~mm}$ respectivamente, las cuales generaron supresión de los anillos de crecimiento de algunos árboles. También, en esos años, se observó una mayor dinámica geomorfológica con importantes cambios en la cubierta vegetal, observados en las imágenes de satélite de Google Earth ${ }^{\mathrm{TM}}$. En el 2013 los árboles registraron ligeras supresiones y los canales permanecieron activos. A partir del 2014 la especie mostró realces y, en las imágenes, se observó una recolonización de árboles, lo que sugiere una aparente estabilización geomorfológica. Los resultados expuestos demuestran el potencial de Juniperus deppeana en México para estudios dendrogeomorfológicos, mismos que se pueden utilizar para enriquecer los planes de prevención y mitigación de peligros naturales en la zona de estudio.

Palabras clave: flujos de escombros; dendrogeomorfología; Juniperus deppeana; Ixtacamaxtitlán; Puebla; México.

\footnotetext{
ABSTRACT

Owing to their potential consequences, such as the disaster triggered by hundreds of landslides in October 1999 in the mountain range Sierra Norte de Puebla, mass movement processes are among the most significant geomorphological hazards in Mexico. In this paper, we presented
}

the reconstruction and analysis of debris flows at two valleys located on the Tenextepecuaco mountain in the Sierra Norte de Puebla, based on geomorphologic and dendrogeomorphic methods. From 37 Juniperus deppeana trees we made a Local Reference Chronology, also to dating and mapping the debris flow events and finally for determine the stability/instability of the landforms using the age of the trees. The comparative anal$y$ sis of the maximum rainfall series in 24 hours, for the period from May to October from 1992 to 2013, and the tree-ring width index suggested that in August 2007 and August 2010 two channels of the western valley were reactivated triggered by heavy rainfall amounting 93 and $56 \mathrm{~mm}$, respectively. As a result of such event, some tree-rings series recorded a growth suppression, and that was also observed in satellite images by Google Earth ${ }^{T M}$ through changes in the vegetation cover. Other trees showed a less growth suppressions in 2013 and the channels were kept active. Since 2014, some trees showed a growth release, and recolonization of trees was also identified in the satellite imagery by Google Earth ${ }^{T M}$, suggesting an apparent geomorphological stability. The applied methodology showed the potential of Juniperus deppeana to be used for dendrogeomorphic studies in México, also in others geomorphic context. Additionally, particular results of the study can contribute to the existing efforts on prevention and mitigation of natural hazards within the regional context.

Key words: debris Flow; dendrogeomorphology; Juniperus deppeana; Ixtacamaxtitlán; Puebla; Mexico.

\section{INTRODUCCIÓN}

Los procesos de remoción en masa son una de las amenazas geomorfológicas más importantes en México y el mundo (AlcántaraAyala y Murillo-García, 2008). Si bien estos procesos pueden ocurrir de manera natural en el relieve, la transformación de las laderas por el cambio de uso de suelo puede ejercer una influencia considerable en su dinámica e inestabilidad geomórfica (Alcántara-Ayala et al., 2006). El crecimiento de la población, el desarrollo de los asentamientos humanos en áreas potencialmente inestables, los procesos de urbanización que carecen de una planificación adecuada, así como la ausencia de ordenamiento territorial, son factores de riesgo que deben ser atendidos de manera integrada (Ismail-Zadeh y Cutter, 2015). El conocimiento 
de la distribución espacio-temporal de los diversos tipos de procesos de remoción en masa es fundamental para poder realizar análisis de amenaza y riesgo, por lo que es necesario documentar tanto procesos actuales como históricos.

Los flujos de escombros son un tipo de proceso de remoción en masa que está relacionado con desastres de gran magnitud en el mundo. Generalmente ocurren en ambientes escarpados con un régimen de lluvias importante y son responsables del balance de sedimentos en las cuencas. Además, su grado de peligrosidad está en función de variables como la velocidad, distribución espacial y baja predictibilidad (Jakob y Hungr, 2005). Estos fenómenos se pueden definir como una mezcla de agua, fragmentos de roca, detritos, suelo y restos de biomasa que se desplazan ladera abajo siguiendo el curso de las corrientes y en ocasiones sobre las laderas abiertas sin confinamiento lateral (Clague, 2013), adquiriendo el comportamiento de un fluido al aumentar su velocidad y disminuir la resistencia al cizallamiento (Takahashi, 2014).

En general, hay cuatro orígenes de los flujos de escombros: (i) por un deslizamiento que se convierte en un flujo de escombros en su descenso por las laderas; (ii) por desprendimiento de material de las laderas en la parte superior, que interactúa con las corrientes de bajo orden convirtiéndose en un flujo de escombros; (iii) por erosión hídrica y acumulación de sedimentos en las partes cóncavas, seguido de una fase de incisión generando un flujo de escombros; (iv) por acarreo de materiales en las partes cóncavas del relieve por un flujo de agua producto de las lluvias; a lo largo del canal se puede generar una presa o tapón de escombros, que posteriormente es liberado (Brayshaw y Hassan, 2009; Larsen et al., 2006; Morino et al., 2018).

La ocurrencia de procesos de remoción en masa se ha concentrado históricamente en el centro y sur de México durante la época de lluvias torrenciales de verano que, en muchos casos, son promovidas por la entrada de huracanes en las costas del Pacífico y Atlántico (FrancoRamos et al., 2019a). A pesar de algunos esfuerzos (Murillo-García y Alcántara-Ayala, 2017), dichos procesos no han sido documentados sistemáticamente a nivel municipal, estatal y nacional. Esta tarea requiere no sólo el registro de los procesos actuales, sino también el conocimiento de su frecuencia-magnitud y distribución espacial, ya que estos procesos pueden volver a ocurrir en el futuro.

La compleja dinámica de los procesos de remoción en masa ha involucrado su análisis desde diferentes perspectivas científicas. Entre ellas se encuentran los estudios geológico-geomorfológicos (Alexander y Coppola, 1989; Guzzetti, et al., 2003), los modelos de estadística multivariada (Clerici, et al., 2002; Timilsina, et al., 2014), así como la instrumentación y monitoreo (Costanzoet al., 2015), la modelación, y la percepción remota (Baldo et al., 2009; Murillo-García et al., 2015; Feizizadeh et al., 2017). Recientemente, se han empleado métodos dendrogeomorfológicos, basados en la identificación y datación de disturbios en los anillos de crecimiento de los árboles afectados por procesos geomorfológicos (Alestalo, 1971). Además, este método provee de precisión y exactitud anual o incluso sub-anual, capaz de reconstruir procesos del orden de decenas a cientos de años atrás (Bull, 2007). La dendrocronología se ha aplicado para el análisis de procesos geomorfológicos como deslizamientos (Paolini et al., 2005; Lopez-Saezet al., 2013; Šilhán, 2019), caída de rocas (Stoffel et al., 2005; Mainieri et al., 2019) y flujos de escombros, entre otros eventos.

En México se han reconstruido procesos geomorfológicos en ambientes volcánicos, con base en métodos dendrogeomorfológicos. Destacan los trabajos pioneros de Bollschweiler et al. (2010) que fecharon lahares en el volcán Popocatépetl y el de Stoffel et al. (2011) donde analizaron la frecuencia de caída de rocas en el volcán Iztaccíhuatl. Posteriormente, Franco-Ramos et al. (2013) reconstruyeron la dinámica de lahares en el volcán de Colima. También,
Franco-Ramos et al. (2017) evaluaron el potencial de coníferas de bosque templado para estudios enfocados en las edades mínimas de relieve y de estabilización geomórfica, con base en la edad del arbolado. Recientemente Franco-Ramos et al. (2020) modelaron un evento lahárico a partir de modelos hídricos bidimensionales en combinación con evidencias dendrogeomorfológicas (posición y altura de las cicatrices de impacto en los árboles) en la barranca Jamapa, Pico de Orizaba.

En la Sierra Norte de Puebla los procesos de remoción en masa han ocurrido con mucha frecuencia favorecidos por relieves abruptos, laderas escarpadas, por cambios de uso de suelo, lluvias torrenciales asociadas a huracanes y tormentas tropicales, principalmente del Océano Atlántico. Estos procesos de remoción han sido estudiados por Alcántara-Ayala et al. (2006), a partir del análisis del uso de suelo y empleando imágenes de satélite. Por otro lado, Capra et al. (2003a; 2003b; 2006) estudiaron la relación entre las características estructurales, litológicas y sedimentológicas de los materiales y la dinámica de los procesos de remoción en masa en la Sierra Norte de Puebla. Además, Lugo-Hubp et al. (2005) se enfocaron en el estudio de los cambios morfológicos del relieve y su relación con procesos de ladera recientes. Los objetivos de la presente investigación son: i) identificar y mapear las formas y rasgos del relieve asociado a los flujos de escombros en el municipio de Ixtacamaxtitlán, localizado en la Sierra Norte de Puebla, ii) conocer el potencial dendrocronológico de Juniperus deppeana (J. deppeana) (Steud.) para el fechamiento y análisis de flujos de escombros, iii) evaluar la estabilidad y edad del relieve, con base en la edad del arbolado (edades mínimas de estabilización).

\section{ÁREA DE ESTUDIO}

\section{Localización}

El área de estudio pertenece al municipio de Ixtacamaxtitlán, en la Sierra Norte de Puebla (SNP) que es una sub-provincia geológica y geomorfológica del extremo sur de la Sierra Madre Oriental (SMO) y que limita con las provincias del Eje Neovolcánico y la Planicie Costera del Golfo de México (Figura 1a) (Lugo-Hubp et al., 2005) y está constituida principalmente por rocas mesozoicas plegadas, parcialmente cubiertas por rocas volcánicas del Plioceno y Cuaternario (Borja-Baeza y Alcántara-Ayala, 2010). La región se compone de topoformas como sierras, mesetas, valles, lomeríos, llanuras y cañones (Alcántara-Ayala et al., 2017).

Los valles de Ixtacamaxtitlán albergan vegetación de transición del semiseco de las planicies de Tlaxcala y del campo volcánico de los humeros al templado en las partes elevadas de la Sierra Norte de Puebla sobre la cuenca del río Apulco. Al sur y sureste, sobre las localidades de Minatitlán, Escuinapa, Ranchitos y Mexcaltepec, predominan remanentes de bosque de pino y oyamel, mientras que hacia el norte y noreste, sobre la cuenca del río Apulco, prevalecen los bosques de pino-encino. Rumbo al occidente, sobre los cerros de Temascacatzín, Colhua, La Calavera y Zalico, flanqueando la cabecera municipal, predomina el matorral desértico rosetófilo (INEGI, 1998 y 2013). Si bien se han documentado en el estado de Puebla algunos procesos de remoción en masa relacionados con la actividad sísmica, la precipitación derivada de eventos extremos entre los meses de mayo y octubre (Figura 2), es considerada como el principal mecanismo desencadenante de la inestabilidad de laderas (Alcántara-Ayala et al., 2017). Los procesos de remoción en masa que predominan en la zona de interés son la caída de rocas, los deslizamientos y los flujos de escombros. Este tipo de procesos se pudieron apreciar en las vertientes sur y noroeste del Cerro Tenextepecuaco, con una dinámica condicionada por el tipo y disposición de los materiales, y las precipitaciones máximas, como 
a)

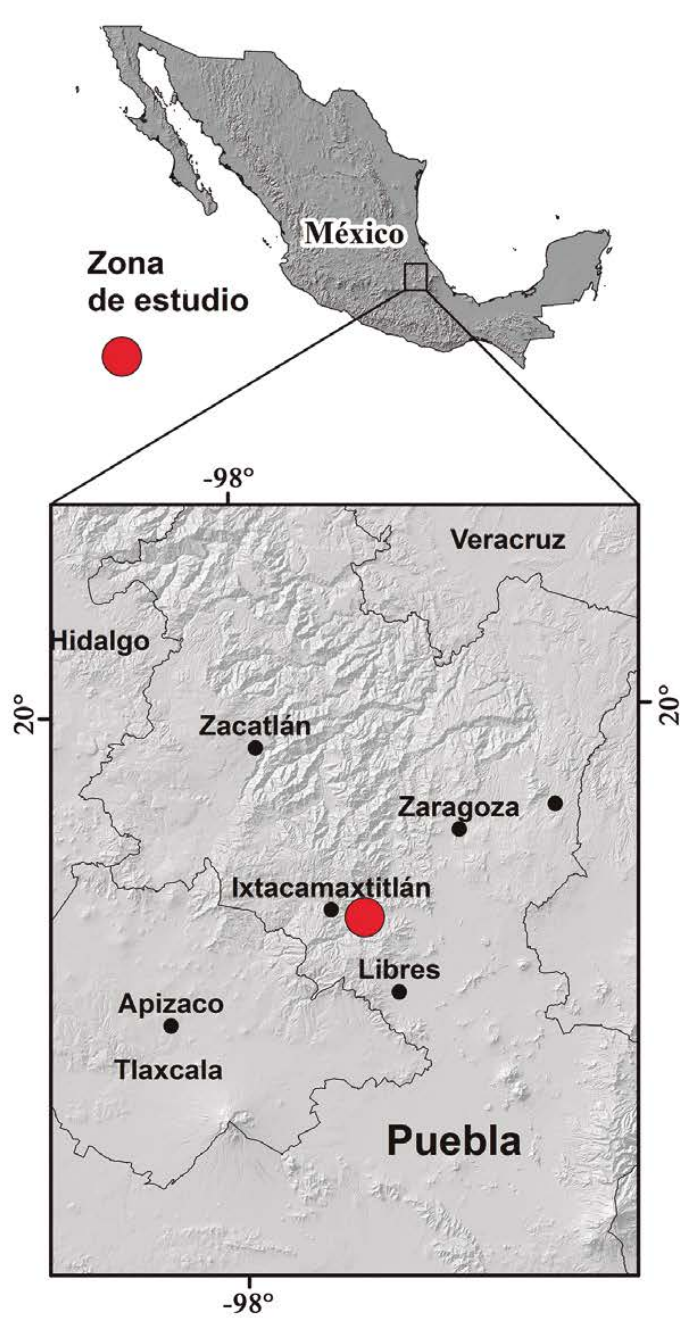

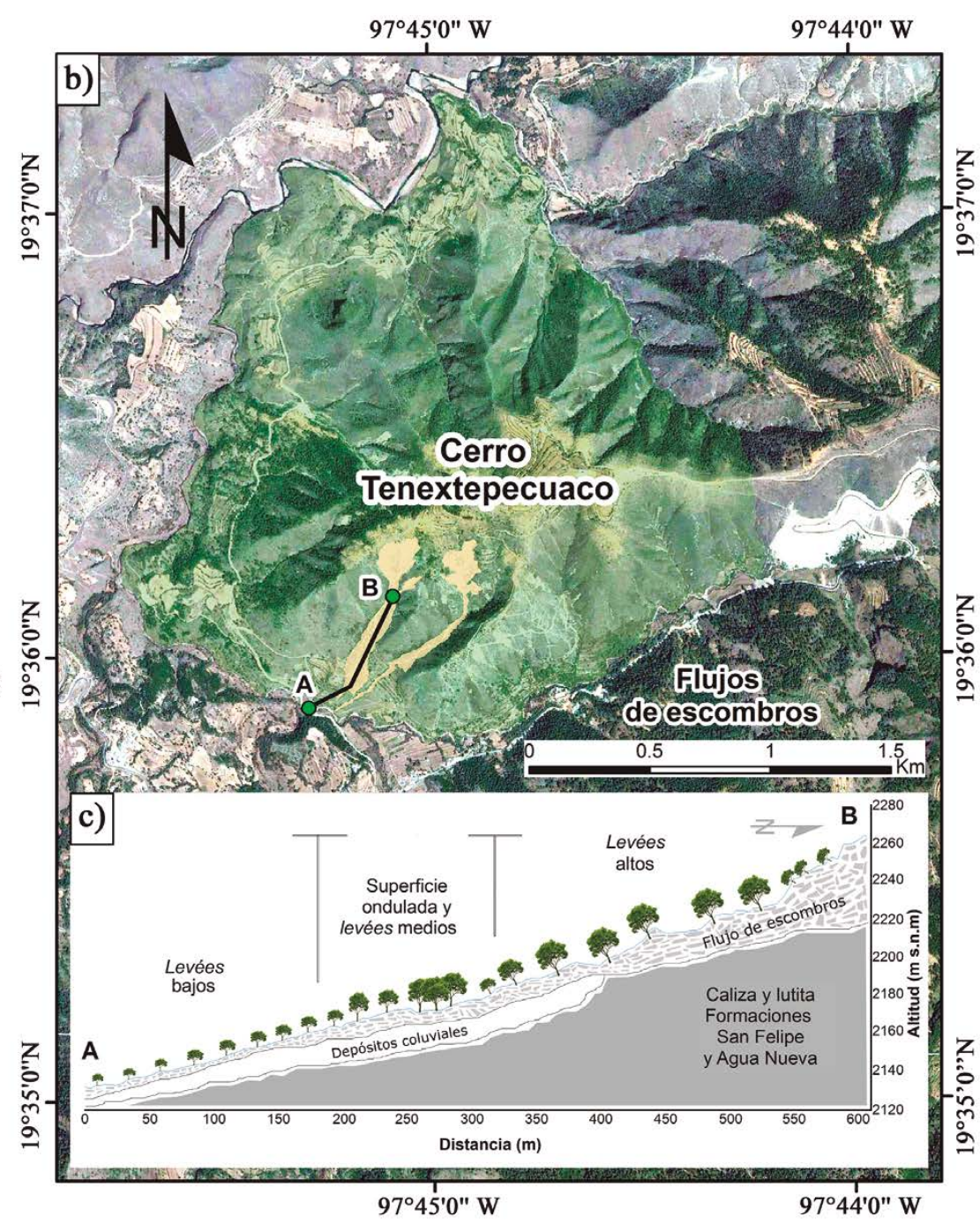

Figura 1. Localización del área de estudio. a) El municipio de Ixtacamaxtitlán se encuentra en el extremo sur de la Sierra Norte de Puebla. b) Los flujos de escombros se distribuyen sobre la vertiente sur del Cerro Tenextepecuaco. c) Perfil longitudinal donde se muestran las principales unidades geomorfológicas.

factores detonantes.

Los flujos de escombros analizados se localizan en dos valles contiguos, (valle poniente, VP; valle oriente, VO) en el flanco sur del Cerro Tenextepecuaco, $7 \mathrm{~km}$ al este de la cabecera municipal de Ixtacamaxtitlán, Puebla, a una altitud de 2250 m s.n.m; estos flujos cubren una superficie de $103427 \mathrm{~m}^{2}$ (Figura 1b). El principal flujo de escombros tiene una longitud, anchura y altura máxima de 850, 145 y $300 \mathrm{~m}$ respectivamente. La zona está colonizada principalmente por Juniperus deppeana y Buddleja cordata, este último predomina sobre la parte noreste del valle poniente (Figura 1c).

La zona de estudio queda comprendida dentro de la SNP, la cual forma parte de la Sierra Madre Oriental, y está conformada principalmente por rocas sedimentarias mesozoicas con intensa deformación debida a procesos de plegamiento y fracturación durante la Orogenia Laramide (Lugo-Hubp, 1990; Eguiluz de Antuñano et al., 2000; Cuéllar-Cárdenas et al., 2012). En el sitio predominan afloramientos de las formaciones Tamaulipas y Agua Nueva-San Felipe, que constan de secuencias de caliza, lutita y arenisca muy deformadas, afectadas por el anticlinal Atecalan y la falla Tateno con edades del Cretácico Temprano al Cretácico Tardío
(SGM, 2012).

\section{METODOLOGÍA}

La metodología para la reconstrucción espacio-temporal de flujos de escombro, con base en el análisis de los disturbios en los anillos de crecimiento de Juniperus deppeana consistió en cuatro etapas: (1) mapeo geomorfológico; (2) estrategias de muestreo en campo; (3) análisis de laboratorio; y (4) cartografía de eventos dendrogeomorfológicos y edad del arbolado. Se emplearon métodos dendrocronológicos reportados por Stokes y Smiley (1968), Phipps, (1985) y Speer (2010), así como los conceptos y criterios de la dendrogeomorfología aportados por Alestalo (1971), Shroder (1980), Braam et al. (1987) y recientemente, Stoffel y Bollschweiler (2008 y 2009) y Stoffel y Corona (2014).

\section{Mapeo geomorfológico}

Se cartografiaron las unidades geomorfológicas en el VP y VO a partir de una imagen de satélite con vista en 3D de Google Earth ${ }^{\mathrm{TM}}$ (Scheffers et al., 2015). La fecha de la imagen fue del 25 de febrero del 2015 con $0.3 \mathrm{~m}$ de resolución. En la generación del mapa de unidades geomorfológicas, se usaron perfiles transversales levantados en campo 


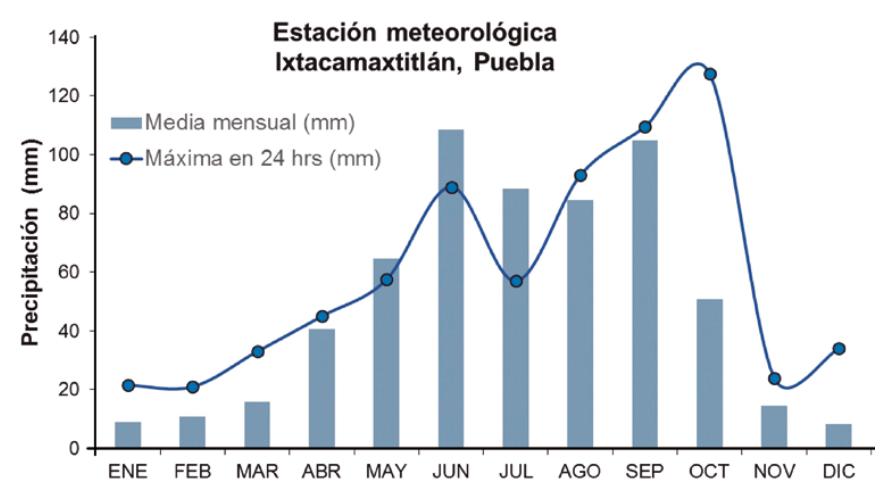

Figura 2. Precipitación media mensual y eventos máximos de lluvia en 24 horas para un periodo de registro de 60 años en la estación meteorológica Ixtacamaxtitlán, en el estado de Puebla. La zona de estudio se ve influenciada por las lluvias de mayo a octubre, donde se dan las condiciones para la generación de procesos de remoción en masa.

con un Sistema de Posicionamiento Global (GPS), una capa de pendientes derivada de un Modelo Digital de Elevación (MDE) construido en un Sistema de Información Geográfica (SIG), así como un mapa de coberturas vegetales y esquemas geomorfológicos realizados en campo.

\section{Estrategias de muestreo en campo}

Durante esta fase se tomaron muestras de árboles con y sin evidencia de disturbios por flujos de escombros. Se barrenaron 37 individuos en los dos valles a una altura promedio de $30 \mathrm{~cm}$, con un taladro Pressler de 16" de longitud y $5.15 \mathrm{~mm}$ de diámetro interior, se recabaron los datos de posicionamiento y altitud. En total se obtuvieron 54 núcleos de árboles, de los cuales se seleccionaron 19 muestras sin anomalías de crecimiento para elaborar una Cronología de Referencia Local (CRL). Posteriormente se utilizaron 26 muestras para fechar y reconstruir la frecuencia de flujos de escombros, y nueve núcleos se descartaron (Tabla 1) por presentar múltiples problemas de fechado como anillos falsos, anillos ausentes, anillos parcialmente ausentes (en cuña) y anillos difusos.

En el caso de los árboles inclinados por los materiales de los flujos de escombros, se colectaron dos muestras, una en la cara $\mathrm{C}$ (pendiente arriba) y otra en la cara D (pendiente abajo) de cada árbol, ya que, en estas circunstancias, se han identificado cambios en el patrón "normal" de crecimiento como anillos excéntricos, madera de reacción y supresiones en el crecimiento.

\section{Análisis de laboratorio}

En laboratorio las muestras fueron preparadas de acuerdo con criterios estandarizados descritos en Stokes y Smiley (1968) y Bräker (2002) para su conteo y fechado, utilizando gráficos de crecimiento o skeleton plots. Una vez que se asignaron fechas a cada anillo de crecimiento de todas las muestras, éstas se midieron utilizando un microscopio estereoscópico, un micrómetro digital VELMEX con precisión de $0.001 \mathrm{~mm}$ y una platina de fase deslizable, así como el software TSAP-Win (Rinn, 2003) (Stokes y Smiley, 1968; Fritts, 1976). En el programa COFECHA (Co-fechado) (Holmes, 1983), se analizaron los resultados de la medición a partir de dos estadísticos, inter-correlación de las series y sensibilidad media, mientras que en ARSTAN (Cook, 1985), se generó una cronología estandarizada obteniendo un Índice de Ancho de Anillo (IAA) con media de $1.0 \mathrm{y}$ varianza constante.

Una vez asignadas las edades finales a todos los árboles, éstos se separaron por unidad geomorfológica. Los levées se separaron en levées bajos (2140 a 2160 m s.n.m.), levées medios (2160 a 2200 m s.n.m.) y
Tabla 1. Número de árboles y núcleos de crecimiento colectados de Juniperus deppeena (Steud.) en los Valles Oriente y Poniente del Cerro Tenextepecuaco.

\begin{tabular}{lcc}
\hline & Árboles & Núcleos de incremento \\
\hline Cronología de referencia local & 12 & 19 \\
Reconstrucción de flujos de escombros & 17 & 26 \\
Núcleos descartados & 8 & 9 \\
Total & 37 & 54 \\
\hline
\end{tabular}

levées altos (2200 a 2300 m s.n.m.); las demás unidades incluyeron las superficies onduladas de la parte media del VP y las terrazas para los dos valles. La edad del arbolado y análisis de los disturbios en los anillos de crecimiento afectados por flujos de escombros se reportó de manera general y por unidad geomorfológica, asociando los conceptos de edad mínima y estabilidad geomorfológica con base en los criterios de Stoffel y Bollschweiler (2008) y Stoffel y Corona (2014). Con la información obtenida del grupo de árboles con disturbios de crecimiento, se generó una base de datos georreferenciada donde se documentó la unidad geomorfológica asociada a cada valle, la clave del árbol, su edad, tipo de evento dendrogeomorfológico (ej. sepultamiento e inclinación) y sus respuestas asociadas (ej. supresión y excentricidad). Con base en esto se realizaron mapas de edad del arbolado y de árboles dañados por los flujos de escombros en el Sistema de Información Geográfica ArcGis 10.3.

Posteriormente se comparó el IAA de los árboles de referencia con el de los árboles que presentaron disturbios de crecimiento a fin de observar cambios atribuidos a eventos de flujo de escombros y finalmente se anexó la curva de lluvias máximas en $24 \mathrm{hrs}$ para el periodo de mayo a octubre de 1992 a 2013 con datos obtenidos del CLICOM (Climate Computing Project, CNA, 2014) con el objetivo de determinar eventos de lluvia torrencial. Los resultados se corroboraron con el análisis de las imágenes de satélite de Google Earth ${ }^{\mathrm{TM}}$ del 2007 al 2015.

\section{RESULTADOS}

\section{Formas y rasgos del relieve}

Los canales fluviales se originaron en la parte superior de cada valle, constituidos de paredes de 2 a $5 \mathrm{~m}$, reduciendo la profundidad de disección hasta la zona de superficies onduladas de la parte media. En estas zonas se reducen a incipientes surcos para después volverse a encajonar hasta su deposición en las partes bajas sobre el canal del río, donde tienen una anchura media de $7 \mathrm{~m}$. En las partes elevadas predominaron bloques de $0.1 \mathrm{a} 0.5 \mathrm{~m}$, mientras que, en las zonas de acumulación, detritos envueltos en una matriz de arcilla y desprovistos de vegetación arbórea, a excepción de la zona media del VP, de menor pendiente e incipiente acumulación de materiales finos (Figura 3).

La parte alta del VP se constituye por una serie de diques pronunciados con anchuras de 1 a $5 \mathrm{~m}$ constituidos de cantos angulosos de caliza y lutita de 0.1 a $0.5 \mathrm{~m}$ a detritos dispuestos en planos de estratificación o también de manera heterogénea. En la zona media se distribuyeron materiales de tamaño menor o igual a $0.3 \mathrm{~m}$ y detritos envueltos en una matriz de arcilla. Las superficies onduladas que corresponden a zonas de baja inclinación en el VP presentaron una serie de micro-levées y montículos de cantos y detritos, así como algunos abanicos, con predominio de árboles de J. deppeana (Sabino), Buddleja cordata (Tepozán) y Fraxinus (Fresno), además de agaves y arbustos (Figura 4). En el caso de las terrazas, en el VP se cartografió una zona marginal al cauce del río con evidencia de formación de suelo $\mathrm{y}$ algunos aportes de material reciente, mientras que para el VO, las terrazas fueron de menor tamaño. 


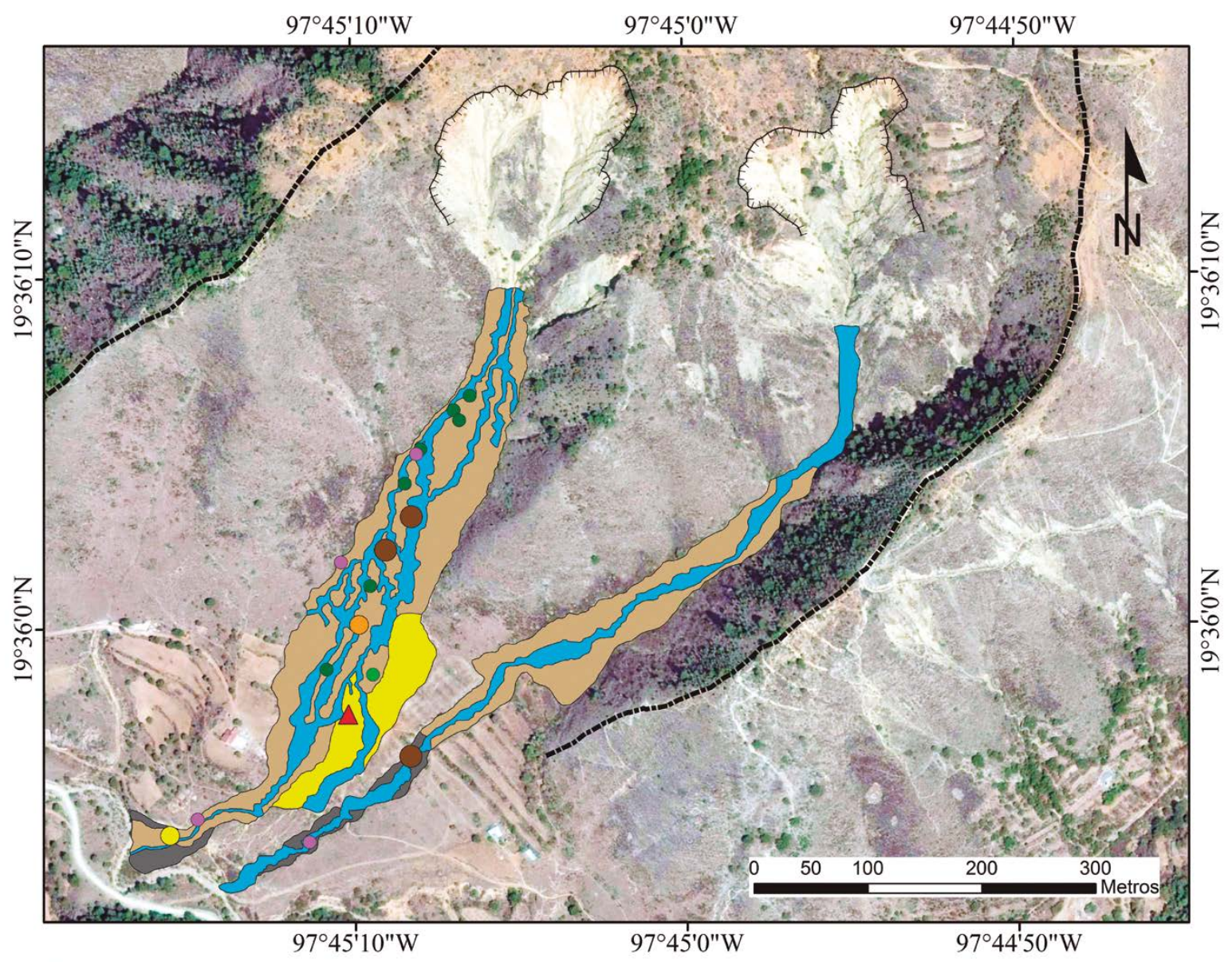

\section{Disturbios de crecimiento}

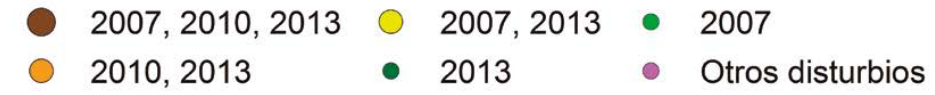

\section{Unidades geomorfológicas}

Canales $\square$ Levées $\square$ Superficies $\square$ Terrazas
fluviales

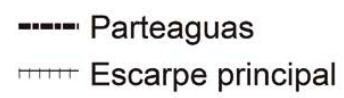

Figura 3. Mapa de unidades geomorfológicas y disturbios de crecimiento en Juniperus deppeana en la zona de estudio. Una supresión importante se generó en el 2007, mientras que algunos árboles no mostraron evidencia en los anillos, a pesar de estar inclinados y parcialmente sepultados.

\section{Potencial dendrogeomorfológico de Juniperus deppeana}

Para la construcción de una Cronología de Referencia Local (CRL), se emplearon datos de 12 árboles exentos de disturbios de crecimiento (Figuras 5a-5d). De acuerdo con el programa COFECHA el valor de inter-correlación de las series fue de 0.24 y el coeficiente de sensibilidad media de 0.32. La media mínima del ancho de anillos fue de $2.64 \mathrm{~mm}$, la media máxima de $5.83 \mathrm{~mm}$ y la media de todas las series de 4.96 $\mathrm{mm}$, mientras que la desviación estándar promedio fue de $1.89 \mathrm{~mm}$. En los árboles de J. deppeana afectados por eventos de sepultamiento e inclinación, se detectaron muestras con anillos suprimidos o excéntricos, como consecuencia de los materiales que ejercen una presión sobre el tronco (Figura 6a, 6b). En este sentido, el $18 \%$ de los árboles muestreados (3 árboles) presentaron supresiones en 2007, 2010 y 2013; mientras que tres individuos presentaron dos eventos, 2010-2013, 2011-2012 y 2007-2013; el 53 \% de éstos (nueve árboles) presentaron un evento y finalmente el $11 \%$ (dos árboles) no presentó reacción al sepultamiento parcial e inclinación (Tabla 2).
Los disturbios fechados en cuatro árboles para el VP y uno para el VO en 2007, concuerdan con una lluvia máxima de $232 \mathrm{~mm}$, para los meses de mayo a octubre (Figura 7).Cabe resaltar la lluvia del 22 de agosto de este año, ya que se registraron $93 \mathrm{~mm}$ en $24 \mathrm{hrs}$, lo que pudo ocasionar la reactivación del canal fluvial localizado en el sector poniente del VP. Además, se observó una disminución en la cubierta vegetal mediante la imagen de satélite de Google Earth ${ }^{\mathrm{TM}}$ en diciembre de 2007 (Figura 8a). El peso de los materiales acarreados por los flujos de escombros, ocasionaron el sepultamiento parcial y por ende la supresión del crecimiento.

Otro periodo importante de lluvias máximas ocurrió en 2010, con $181 \mathrm{~mm}$ de mayo a octubre, resaltando una lluvia torrencial de $56 \mathrm{~mm}$ en sólo $24 \mathrm{~h}$ registrada el 6 de agosto. Esta condición pudo ocasionar otro flujo de escombros en el sector oriente del VP, cuyos materiales sepultaron la base de cuatro árboles en los dos valles generando ligeras supresiones. Esta dinámica geomorfológica se pudo corroborar en la imagen de satélite de Google Earth ${ }^{\mathrm{TM}}$ del mes 


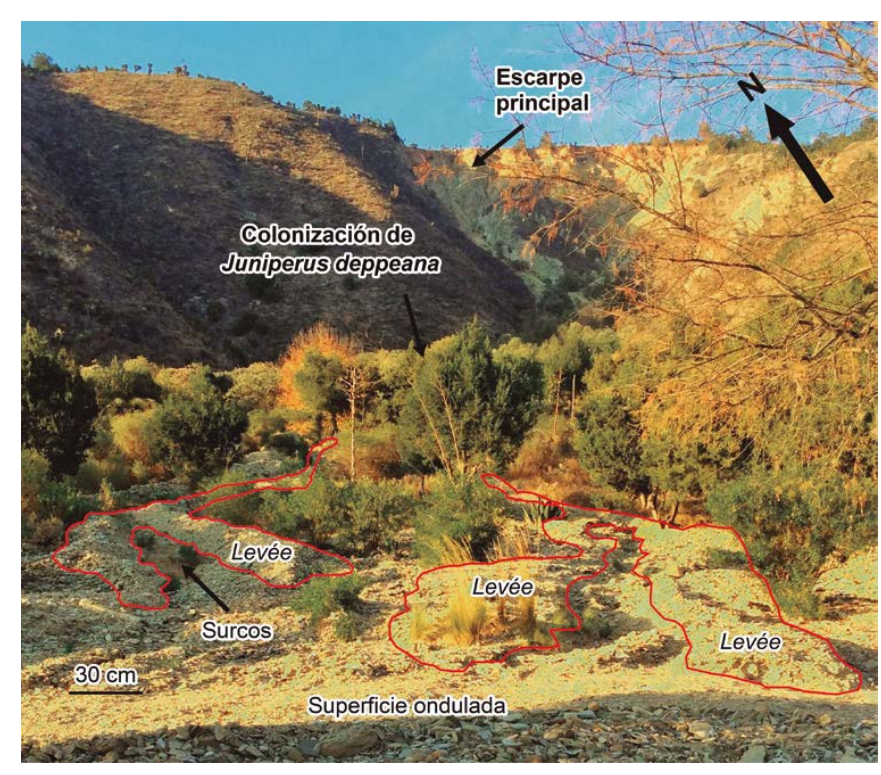

Figura 4. Micro levées, surcos y superficies onduladas sobre la parte media del Valle Poniente, albergando vegetación de Juniperus deppeana, Fraxinus y Buddleja cordata. En la parte superior se observa el escarpe principal.

de mayo de 2011 (Figura 8b), donde se observó una cubierta de vegetación menos densa.

Por otro lado, en las imágenes de satélite de Google Earth ${ }^{\mathrm{TM}}$ de julio del 2012 y de marzo del 2013 (Figura 8c-8d), se observó el ensanchamiento progresivo del canal 2 en el VP, sin embargo, sólo dos árboles mostraron algún tipo de disturbio asociado a un proceso geomorfológico. En la imagen de satélite de Google Earth ${ }^{\mathrm{TM}}$ de marzo del 2013 (Figura 8d), se aprecia actividad geomorfológica en los dos canales principales del VP y hasta noviembre del 2014 (Figura 8e) inicia un ligero incremento de la vegetación arbustiva. Esto coincidió con ligeras supresiones en los anillos de crecimiento de 11 árboles, período en el cual se reportaron $35 \mathrm{~mm}$ de lluvia máxima en 24 horas para el mes de septiembre. A partir del 2014, se incrementó el ancho de los anillos (realces) y no se identificaron disturbios por procesos geomorfológicos a partir de ese año. Además, en las imágenes de satélite de Google Earth ${ }^{\mathrm{TM}}$ posteriores a 2014, se observó una mayor colonización y densidad en la cubierta vegetal (Figura 8f). Lo anterior sugiere una aparente estabilidad geomorfológica por flujos de escombros en los valles, a partir de ese año.

\section{Estabilidad/Inestabilidad del terreno y edades mínimas de relieve}

La edad de los árboles que se localizan en los levées de la parte alta del VP fue de $\leq 15$ años (55\% del total). Además, varios de ellos se encontraron inclinados y sepultados, lo que sugiere una zona con una importante inestabilidad geomorfológica. En la parte media del VP predominaron edades de 16-17 años (50\% del total) y en la parte baja el $80 \%$ de los árboles mostró edades $\leq 13$ años. La superficie ondulada del VP presentó edades de 22-24 años y no se reconocieron árboles con daños, por lo que se consideró como la zona con mayor estabilidad. En las terrazas del VP predominaron edades de 18 años, lo cual sugiere que son contemporáneas, mientras que para el VO se fecharon árboles en dos terrazas con edades máximas de 21 y 14 años. Las edades obtenidas en el estudio son indicadores de la estabilidad/inestabilidad del relieve, además de ofrecer información acerca de la edad mínima de nuevos relieves. En este sentido, los resultados revelaron que por lo menos hace 24 años (1992), el VP no ha presentado actividad geomorfológica considerable. En cambio, el VO se estabilizó hace al menos 21 años (1995), ya que los árboles no presentan evidencia de flujos de escombros o algún otro proceso geomorfológico.

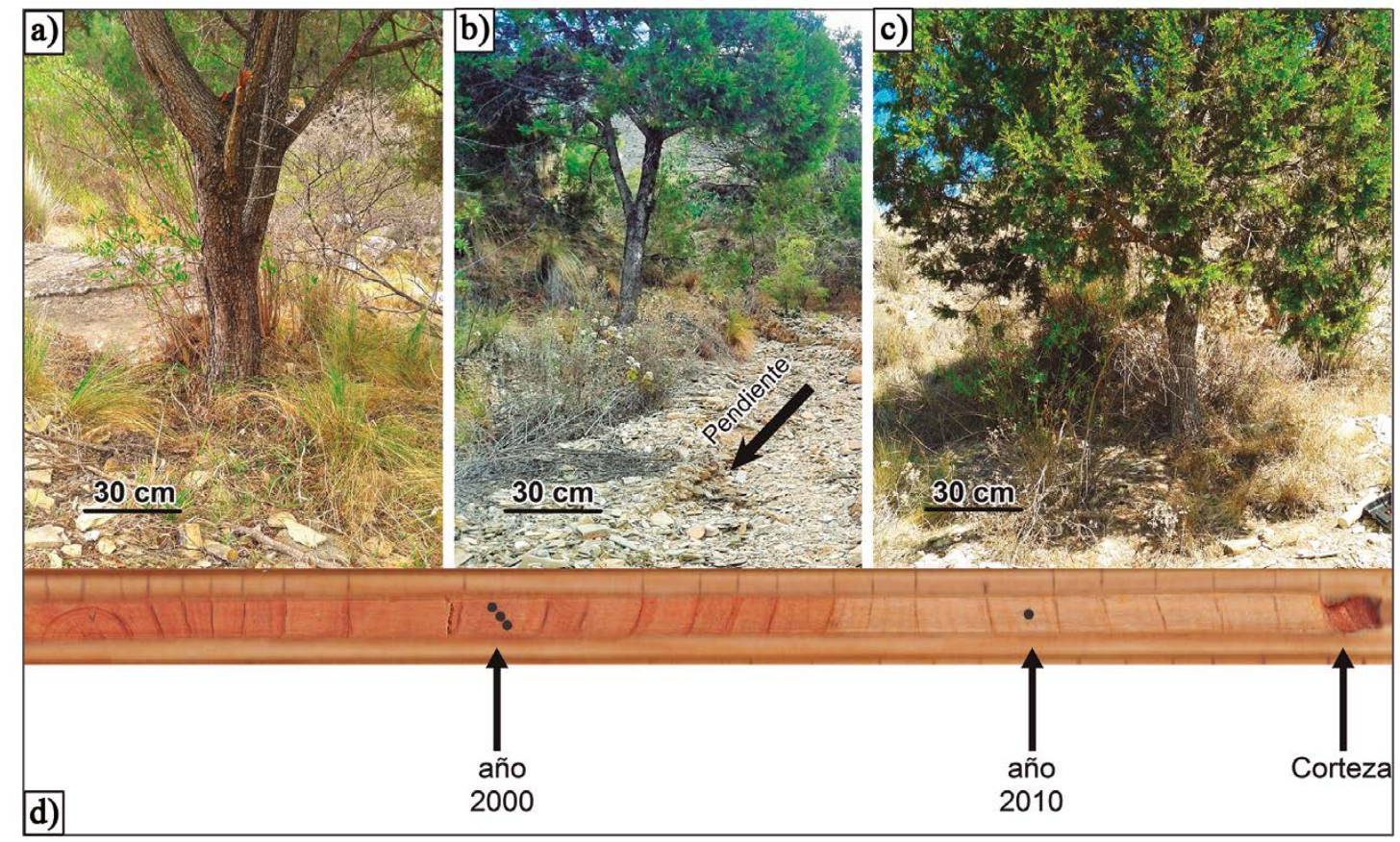

Figura 5. Árboles empleados para la Cronología de Referencia Local (CRL). a) Sitio de muestreo localizado sobre una terraza. b) Árbol situado en los márgenes de un cauce, con relativa estabilidad geomorfológica. c) Muestreo de Juniperus deppeana en un sitio de menor pendiente y formación de suelo. d) Muestra de 24 años de la parte media del VP, empleada para la CRL. 


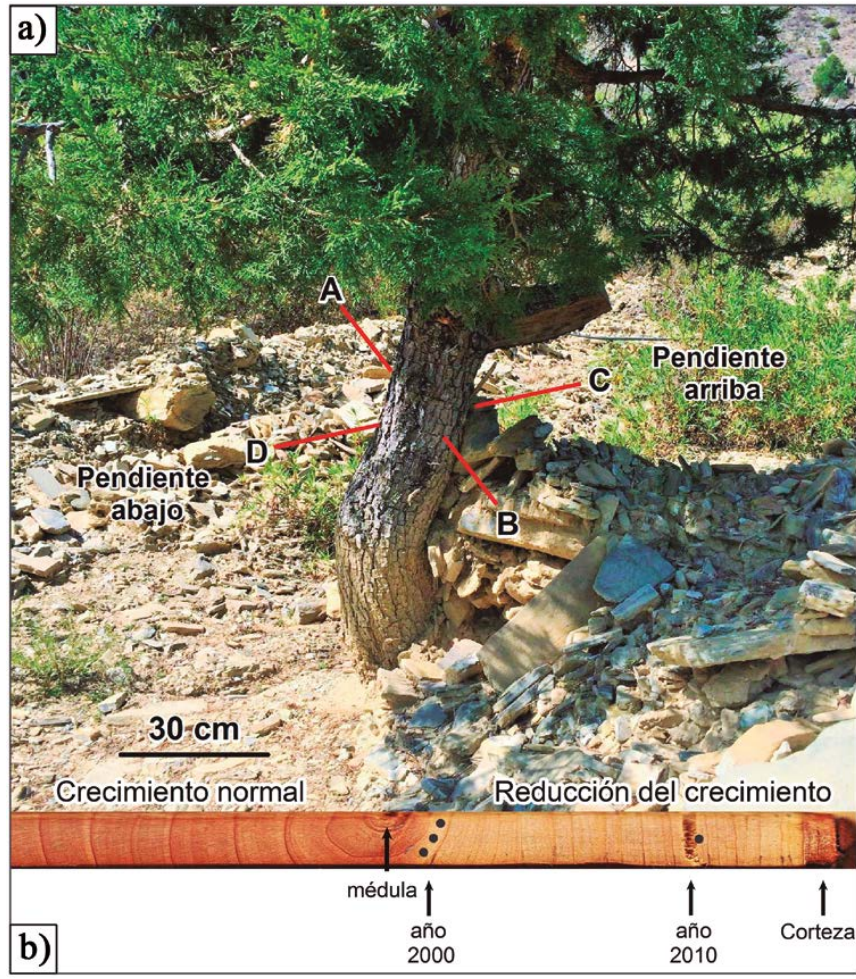

Figura 6. a) Árbol de Juniperus deppeana afectado por un evento de inclinación en la parte media del Valle Poniente (VP) generando una respuesta de excentricidad en la madera. b) Núcleo tomado de un árbol de la parte alta del VP que muestra una reducción del crecimiento en dirección de la pendiente (muestra tomada a $25 \mathrm{~cm}$ de altura).

Con relación a las edades mínimas de los depósitos de flujo de escombros, en los levées que se disponen en la parte alta del VP, los árboles más jóvenes tuvieron una edad de nueve años, es decir, del 2007 y los más viejos una edad de 24 años (1992), con una edad media de 14.6 años ( \pm 4.6 años), por lo tanto, la edad mínima de los levées es de 24 años. Para la zona media del VP la edad de los árboles más jóvenes fue de nueve años (2007), los más viejos tuvieron una edad de 22 años (1994) y una media de 16 ( \pm 5.4 años), de este modo la edad mínima de relieve en este sector es de 22 años. En la parte baja del VP, la edad de los árboles más jóvenes fue de 10 años (2006), los más viejos de 16 años (2000), con una media de 12 años ( \pm 2.5 años), y como resultado una edad mínima de relieve de 16 años. Para la unidad de superficies onduladas del VP, los individuos más jóvenes tuvieron una edad de 23 años (1993), los más viejos de 24 años (1992), con una media de 23.5 ( \pm 0.7 años), por lo que la edad mínima de relieve en esta unidad fue de 24 años. Con relación a las terrazas, se identificaron dos para el VP y cuatro para el VO, las primeras se relacionan con una zona marginal al cauce del río principal y presentaron árboles entre 14 (2002) y 18 años (1998), con una media de 16.7 años ( \pm 2.3 años), por lo tanto, la edad mínima de las terrazas fue de 18 años. En cambio, los árboles de las terrazas del VO mostraron una edad entre 14 (2002) y 21 años (1995), con una media de 16.3 años ( \pm 4 años) y una edad mínima de relieve de 21 años (Figura 9).

\section{DISCUSIÓN}

La respuesta de Juniperus deppeana a los eventos de sepultamiento e inclinación por flujo de escombros en los valles VP y VO en la SNP, fue en forma de supresiones de crecimiento y anillos excéntricos. Este tipo de disturbios en los anillos de crecimiento también se han reportado en especies de bosque templado, en ambientes volcánicos asociados a la dinámica de lahares (Bollschweileret al., 2010; Franco-Ramos et al., 2013, 2016b). En otros contextos geomorfológicos, las supresiones y anillos excéntricos son muy comunes y útiles para fechar avalanchas de nieve (de Bouchard d'Aubeterreet al., 2019).

El análisis comparativo de las curvas de disturbios y las lluvias máximas en 24 h reveló que en agosto de 2007 y 2010 se reactivaron dos canales del VP por las intensas lluvias, los cuales quedaron registrados en los anillos de crecimiento de J. deppeana y también se pudo corroborar con las imágenes de satélite de Google Earth ${ }^{\mathrm{TM}}$ (Figura 8a, 8b). Para el año 2012, si bien se observa una mayor dinámica geomorfológica a partir del ensanchamiento del canal 2, determinado en las imágenes de satélite (Figura 8c, 8d), sólo dos árboles fechados mostraron una respuesta en los anillos de crecimiento que pudiera corresponder con una lluvia máxima en $24 \mathrm{~h}$ de $46 \mathrm{~mm}$ en agosto de ese año. Para el año 2013, se analizaron las imágenes de Google Earth ${ }^{\mathrm{TM}}$ de marzo de 2013 y noviembre de 2014 (intervalo que incluye el periodo de crecimiento del árbol) (Figura 8d, 8e), donde se aprecian los dos canales del VP con actividad geomorfológica, situación que se reflejó en los anillos de crecimiento con ligeras supresiones. A partir del 2014, se registró un realce del crecimiento en los anillos y una mayor cobertura vegetal en las imágenes de satélite de Google Earth ${ }^{\mathrm{TM}}$ (Figura 8f), lo que sugiere el inicio de una fase de estabilización geomorfológica.

Los datos de lluvia máxima en 24 horas derivados de la estación Ixtacamaxtitlán del CLICOM ( $\pm 8 \mathrm{~km}$ de distancia), en un periodo de análisis de 22 años se pudieron observar tres eventos torrenciales. El primero ocurrió en octubre de 1999 donde se reportaron $127 \mathrm{~mm} / 24 \mathrm{~h}$, sin embargo, los árboles colectados no registraron el evento. Esto pudo deberse a que los árboles existentes para ese momento no fueron alcanzados por algún proceso geomorfológico (flujo de escombros) o, posiblemente, los árboles muestreados se establecieron después del evento torrencial de 1999, por lo tanto, no se encontraron suficientes registros dendrogeomorfológicos. El segundo evento torrencial se presentó en agosto de 2007 con una lluvia de $93 \mathrm{~mm} / 24 \mathrm{~h}$. Para este evento sí se observaron supresiones de crecimiento en cinco árboles en los dos valles. La tercera lluvia torrencial sucedió en junio del 2008 con $89 \mathrm{~mm} / 24 \mathrm{~h}$, sin embargo, no fue posible identificar disturbios dendrogeomorfológicos en J. deppeana que valide la ocurrencia de algún proceso de remoción en masa para la zona de estudio.

Por otro lado, este trabajo reveló una correspondencia entre la distribución de las unidades geomorfológicas, la estabilidad del terreno y la colonización de los árboles en los valles de estudio. En los levées altos del VP, predominaron árboles jóvenes con una edad promedio de 14.6 años, mientras que en los levées medios la edad promedio aumentó a 16 años, y finalmente en los levées bajos el promedio de edad fue de 12 años. En las superficies onduladas de la parte media del VP se identificaron los árboles más viejos con 24 años y un promedio de 23.5, siendo la zona con mayor estabilidad geomorfológica. Así mismo, las edades de los árboles muestreados en las terrazas del VP mostraron mayor homogeneidad en comparación con las del VO, lo cual sugiere una mayor inestabilidad de estas últimas, no obstante, el número de muestras fue menor que en las demás unidades.

Con base en el análisis dendrocronológico de 12 árboles de Juniperus deppeana en el sitio de estudio, se obtuvo una inter-correlación de las series de acuerdo con el programa COFECHA de $0.24(P<0.01)$ es decir, más bajo del valor de significancia de COFECHA que es de $0.32(P<0.01)$.

Este valor, incluso fue más bajo en comparación con otras investigaciones en México (Villanueva-Díaz et al., 2016 y MolinaPérez, 2018). Esta situación se puede deber a factores como la altitud 
Tabla 2. Se observa la información dendrogeomorfológica de los árboles muestreados (17), la cual se compone por la clave del sitio, un identificador y el número de muestras tomadas por árbol [DES1-33 (1)]. Se agrega el valle, la unidad geomorfológica a la que pertenece, la edad en años y el registro de supresión (X) del 2007 al 2015. En los levées altos predominaron una mayor cantidad de supresiones en el 2013, mientras que en las partes bajas los árboles registraron varios eventos.

\begin{tabular}{|c|c|c|c|c|c|c|c|c|c|c|c|}
\hline Unidad & 总 & $\begin{array}{l}\text { 窇 } \\
\text { 总 }\end{array}$ & હે̊ & \&્స & ठ્ণ & 옥 & $\overline{\text { ¿ }}$ & $\stackrel{\sim}{\stackrel{\sim}{*}}$ & $\stackrel{m}{\stackrel{n}{3}}$ & $\stackrel{\Delta}{\stackrel{\sim}{*}}$ & $\stackrel{n}{\circ}$ \\
\hline \multicolumn{12}{|l|}{ Valle Poniente } \\
\hline \multirow{10}{*}{ Levée alto } & DES1-33 (1) & 12 & $X$ & & & $X$ & & & $X$ & & \\
\hline & DES1-31 (1) & 17 & & & & & & $x$ & & & \\
\hline & DES1-32 (3) & 12 & & & & & & & $x$ & & \\
\hline & DES1-34 (1) & 11 & $x$ & & & $x$ & & & $x$ & & \\
\hline & DES1-35 (1) & 9 & & & & & & & $x$ & & \\
\hline & DES1-37 (2) & 9 & & & & & & & $x$ & & \\
\hline & DES1-38 (3) & 15 & & & & & & & & & \\
\hline & DES1-40 (1) & 17 & & & & & & & $x$ & & \\
\hline & DES1-41 (1) & 24 & & & & & & & $x$ & & \\
\hline & DES1-42 (2) & 19 & & & & & & & $x$ & & \\
\hline \multirow[t]{3}{*}{ Levée medio } & DES1-22 (1) & 9 & & & & & & & $x$ & & \\
\hline & DES1-24 (1) & 22 & & & & $x$ & & & $x$ & & \\
\hline & DES1-27 (4) & 17 & $X$ & & & & & & & & \\
\hline \multirow[t]{2}{*}{ Levée bajo } & DES1-11 (1) & 10 & & & & & $x$ & $x$ & & & \\
\hline & DES1-9 (1) & 10 & $x$ & & & & & & $x$ & & \\
\hline \multicolumn{12}{|l|}{ Valle Oriente } \\
\hline Terraza & DES2-7 (1) & 14 & $x$ & & & $x$ & & & $x$ & & \\
\hline Canal & DES2-13 (1) & 7 & & & & & & & & & \\
\hline
\end{tabular}

que influye en el grado de sensibilidad de la especie (Magre et al., 2015), así como el tamaño y tipo de muestras colectadas (virutas). Otras investigaciones reportadas para el género Juniperus, arrojan valores de inter-correlación que van de 0.22 en Juniperus thurifera (Rozas y Olano, 2013) a 0.86 en Juniperus osteosperma (Derose et al., 2016). Estos resultados sugieren que varias muestras de $J$. deppeana presentaron problemas de crecimiento irregular, que puede deberse a condiciones de perturbación por procesos geomorfológicos como la reptación, deslizamientos, procesos erosivos, entre otros, que operan en la zona de estudio, cuestiones que deberán afinarse para un óptimo desempeño en el trabajo de campo. Además, la especie también presentó anillos falsos, los cuales se pueden explicar a partir de la producción intermitente de células de madera tardía debido al estrés por las sequías (Copenheaver et al., 2006, Speer, 2010). Otros problemas detectados durante el proceso de fechado fueron anillos ausentes y parcialmente ausentes (en cuña), anillos difusos y micro anillos, esto debido al grado de

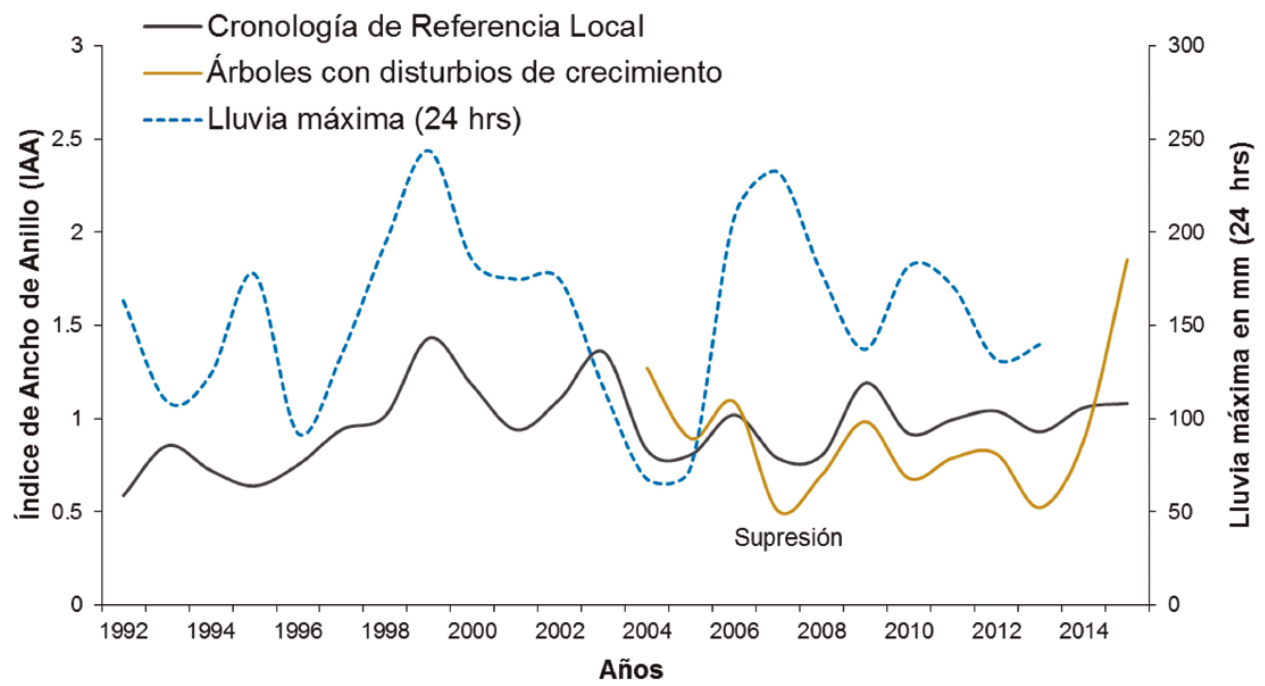

Figura 7. Comparación de las curvas de la Cronología de Referencia Local (línea negra) y la de los árboles con disturbios de crecimiento (línea café). En el año 2007 hubo una importante supresión en los anillos de crecimiento de la especie, mientras que la curva de lluvias máximas (línea azul) de mayo a octubre se elevó hasta los $232 \mathrm{~mm}$. Específicamente se refiere a un evento de $93 \mathrm{~mm} / 24 \mathrm{~h}$ para el mes de agosto. Otro posible evento ocurrió en el 2010. 



Figura 8. Dinámica de los canales de la parte media y alta del flujo de escombros. a) Diciembre del 2007, b) mayo del 2011, c) julio del 2012, d) marzo del 2013, e) noviembre del 2014, f) febrero del 2015.

excentricidad del tronco, y que podría mejorarse al tomarse secciones transversales, principalmente de árboles muertos (Cerano-Paredes et al., 2019). A pesar de las dificultades para su fechado, la especie es capaz de responder a perturbaciones por flujos de escombros detonados por lluvias intensas que ocasionan su sepultamiento e inclinación. Cabe mencionar, que en el trabajo de campo no se detectaron árboles descortezados de J. deppeana, característica muy común en los árboles afectados por flujos de escombros (Stoffel y Corona, 2014) y lahares (Franco-Ramos et al., 2020).

En el contexto internacional, además del uso de coníferas con fines dendrogeomorfológicos, se han explorado especies de latifoliadas como Quercus pubescens Willd, Hacer opalus Mill, Alnusincana, Betulapendula, Salixcaprea entre otros (Favillier et al., 2015; Arbellay et al., 2010). En el caso del género Juniperus, si bien se han generado investigaciones en el contexto climático con especies como Juniperus tibetica y Juniperus scopulorum (Deng y Zhang, 2015; Spond et al., 2014), no hay investigaciones de Juniperus deppeana como indicador para el fechamiento y reconstrucción de la frecuencia de procesos geomorfológicos, por lo que esta investigación demuestra viabilidad para su uso con fines de reconstrucción de eventos geomorfológicos del pasado.

En México se han usado distintas especies de coníferas de bosque templado con gran potencial dendrogeomorfológico como el Abies religiosa (Bollschweiler et al., 2010; Franco-Ramos et al., 2016a y 2016b, 2019a), Pinuss sp (Bollschweiler et al., 2010; Stoffel et al., 2011; FrancoRamos et al., 2013, 2017, 2019a), Alnus jorullensis (Franco-Ramos et al., 2019b) y Juniperus monticola (Alcalá-Reygosa et al., 2018). Aún con las limitaciones y problemas de fechado del Juniperus deppeana reportados por Molina-Pérez (2018), se comprobó que la especie tiene potencial para aportar información en cuanto a la dinámica de procesos geomorfológicos en rangos altitudinales menores a los $2500 \mathrm{~m}$ s.n.m., en el centro de México (Adams, 2014).
Si bien, en este estudio el muestreo de J. deppeana fue limitado y se obtuvo poca evidencia por flujos de escombros, sugerimos que la especie es sensible y fechable, por lo tanto, puede servir para reconstruir procesos geomorfológicos de los últimos cientos o decenas de años atrás en México; siempre y cuando se realice una adecuada estrategia de muestreo dendrogeomorfológico, un tamaño de muestra representativa (mínimo 50 árboles) y por lo menos cuatro núcleos con barreno Pressler por cada individuo en las distintas caras del tronco, así como en los distintos sectores de los valles o barrancas de estudio.

\section{CONCLUSIONES}

La identificación y mapeo de unidades geomorfológicas, así como su relación con parámetros dendrocronológicos del J. deppeana, permitió fechar algunos flujos de escombros (2007, 2010 y 2013) y, a partir de la edad del arbolado, asignar edades mínimas de relieve (levées, superficies onduladas y terrazas), así como proponer algunas fases de estabilización geomórfica.

Dentro del contexto dendrocronológico, la especie presentó problemas de crecimiento y dificultades para el fechado que tiene relación con factores exógenos locales como la pendiente, la calidad del sustrato, diversos procesos geomorfológicos, etc. o bien, con fenómenos climáticos regionales como las sequías en el centro del país. Sin embargo, la especie fue capaz de proveer información clave para la reconstrucción de flujos de escombros, a partir de las supresiones y excentricidad de los anillos de crecimiento. Estos disturbios se pudieron cartografiar con el objetivo de reconocer zonas con mayor inestabilidad del terreno.

La combinación de parámetros como la distribución de edades y número de disturbios en árboles de J. deppeana colonizando los depósitos, son indicadores de la estabilidad del terreno, ya que proveen 


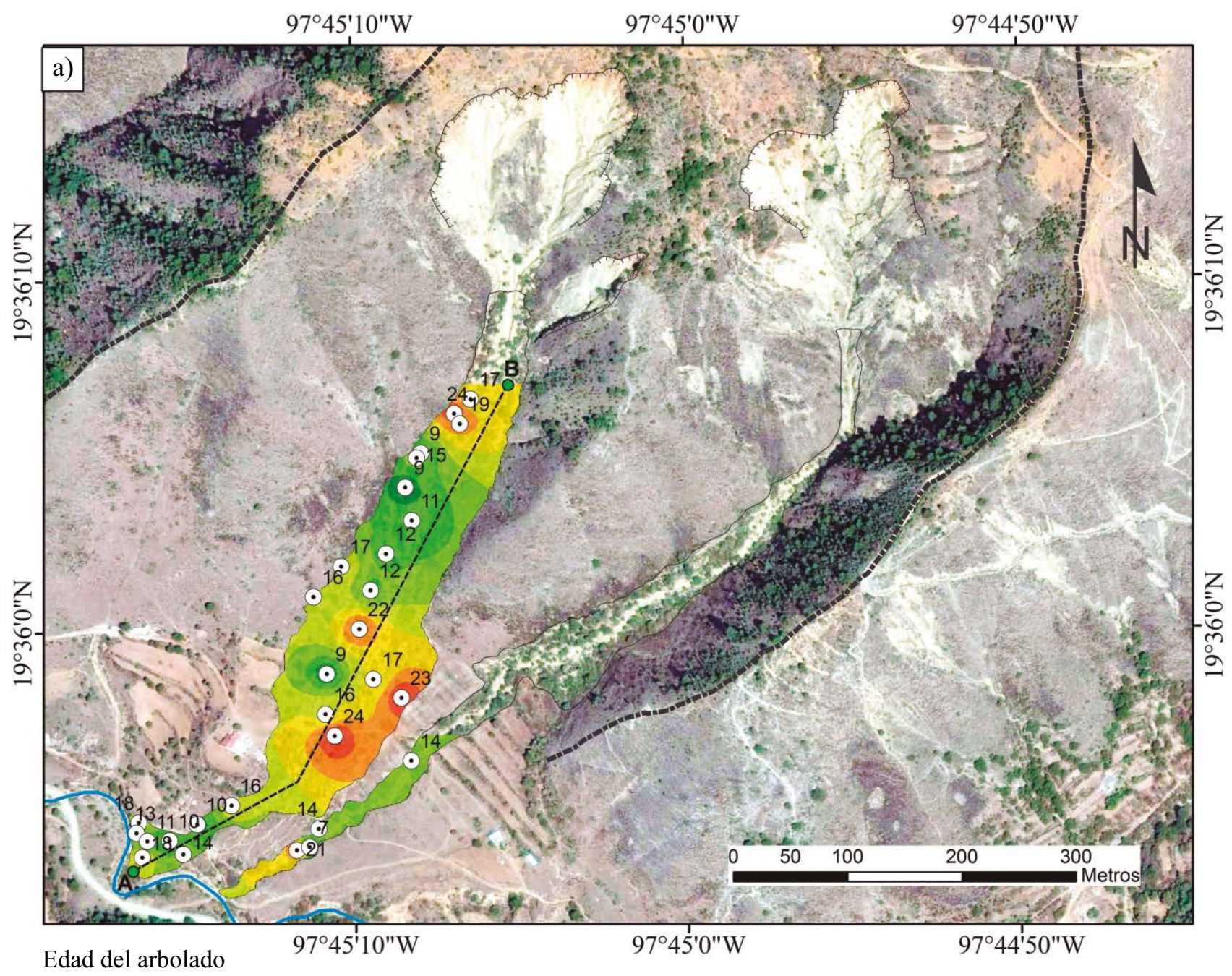

Edad del arbolado

Leyenda

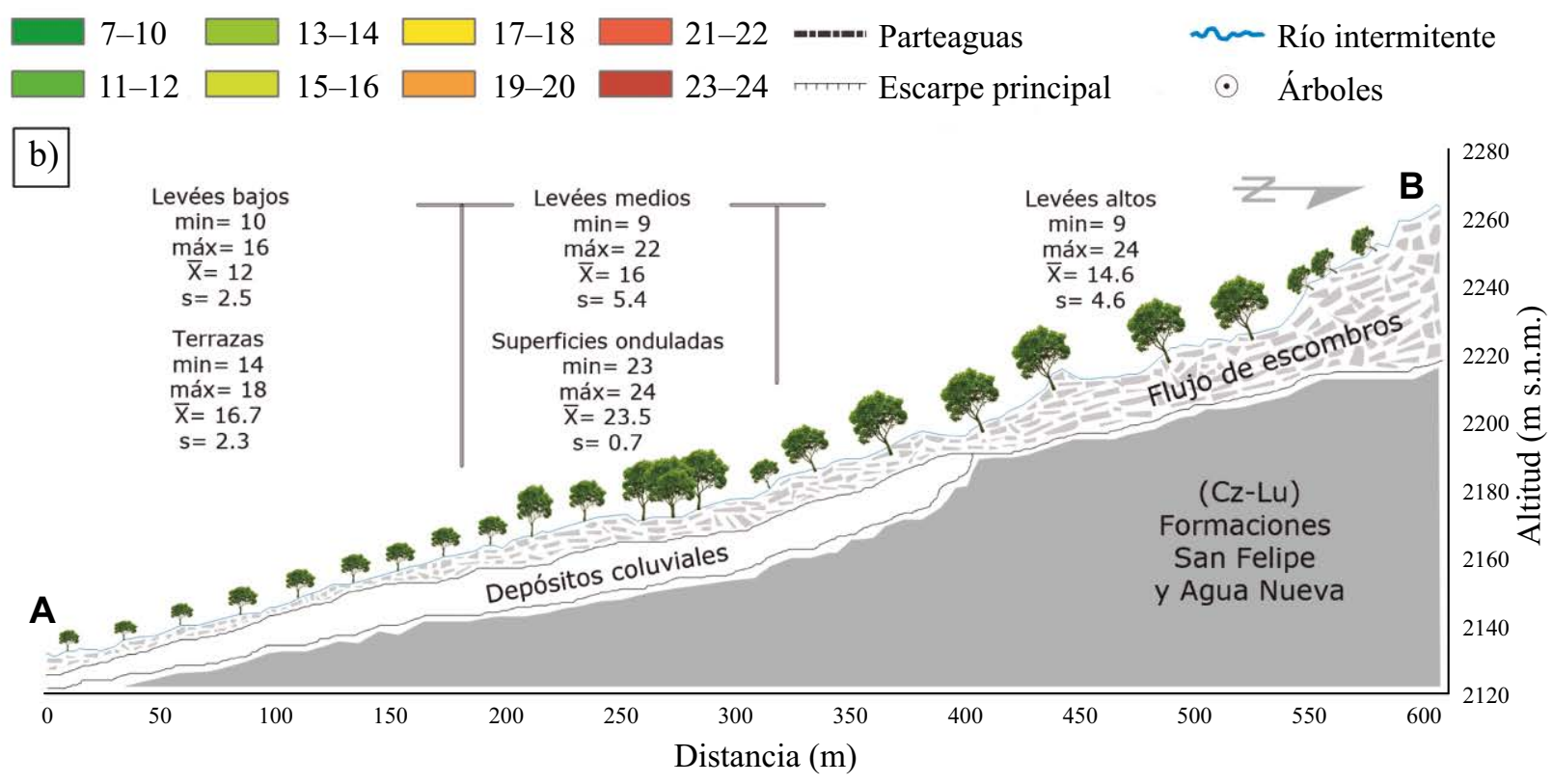

Figura 9. Distribución espacial de la edad máxima del arbolado en el VP y VO. a) Mapa de la edad de Juniperus deppeana en los valles del Cerro Tenextepecuaco. Se empleó una interpolación Spline en un Sistema de Información Geográfica (SIG). b) Perfil longitudinal (sur a norte) del flujo de escombros del Valle Poniente (VP). La edad del arbolado más viejo o máxima corresponde a la edad mínima del relieve o estabilización geomórfica. 
información sobre el último evento que arrasó la vegetación en los valles. Los resultados revelaron que por lo menos hace 24 años en el Valle Poniente, y 21 años para el Valle Oriente, no se han presentado flujos de escombros de gran magnitud. Esta información es de vital importancia para la generación de inventarios y mapas de peligro por flujos de escombros en la Sierra Norte de Puebla, ya que en la mayoría de los casos se desconoce el régimen de eventos en esta región con elevada vulnerabilidad ante procesos de esta índole durante la temporada de lluvias, convirtiéndose así en una herramienta útil en el análisis del riesgo, y potencialmente extensible a otras regiones de México.

\section{AGRADECIMIENTOS}

Los autores agradecen al Dr. Lorenzo Vázquez Selem por el uso de su equipo de medición y análisis dendrocronológico. Un agradecimiento especial al Dr. Ángel Francisco Nieto Samaniego, al Dr. Luis Ángel Rodríguez Sedano, así como al árbitro anónimo, por sus excelentes recomendaciones que permitieron afinar el manuscrito original. Finalmente queremos agradecer a Oscar Ramírez y Juan Pablo, por su apoyo durante el trabajo de campo.

\section{REFERENCIAS}

Adams, R.P., 2014, Junipers of the world: the genus Juniperus: Trafford Publishing, 1-422.

Alcalá-Reygosa, J., Palacios, D., Schimmelpfennig, I., Vázquez-Selem, L., GarcíaSancho, L., Franco-Ramos, O., Villanueva, J., Zamorano, J., Aumaitre, G., Bourlès, D., Keddadouche, K., 2018, Dating late Holocene lava flows in Pico de Orizaba (Mexico) by means of in situ-producedcosmogenic ${ }^{36} \mathrm{Cl}$, lichenometry and dendrochronology: Quaternary Geochronology 47, 93-106.

Alcántara-Ayala, I.,Murillo-García, F.G., 2008, Procesos de remoción en masa en México: hacia una propuesta de elaboración de un inventario nacional: Investigaciones Geográficas 66, 47-64.

Alcántara-Ayala, I., Esteban-Chávez, O., Parrot, J.F., 2006, Landsliding related to land-cover change: A diachronic analysis of hillslope instability distribution in the Sierra Norte, Puebla, México: Catena 65, 152-165.

Alcántara-Ayala I., Garnica-Peña, R.J., Coll-Hurtado, A., Gutiérrez Vázquez de MacGregor, M. T., 2017, Inestabilidad de laderas en Teziutlán, Puebla. Factores inductores del riesgo de desastre: Instituto de Geografía, Universidad Nacional Autónoma de México, 223 pp.

Alestalo, J., 1971, Dendrochronological interpretation of geomorphic processes: Fennia-International Journal of Geography, 105, 1-140.

Alexander, D., Coppola, L., 1989, Structural Geology and the Dissection of Alluvial Fan Sediments by Mass Movement: An Example from the Southern Italian Apennines: Geomorphology 2, 341-361.

Arbellay, E., Stoffel, M., Bollschweiler, M., 2010, Dendrogeomorphicreconstruc tionofpastdebris-flowactivityusinginjuredbroad-leavedtres:Earth Surface Processes and Landforms, 35, 399-406.

Baldo, M., Bicocchi, C., Chiocchini, U., Giordan, D., Lollino, G., 2009, LIDAR monitoring of mass wasting processes: The Radicofani landslide, Province of Siena, Central Italy: Geomorphology 105, 193-201.

Bollschweiler, M., Stoffel, M., Vázquez-Selem, L., Palacios, D., 2010, Tree-ring reconstruction of past lahar activity at Popocatépetl Volcano, México: The Holocene 20, 265-274.

Borja-Baeza, R.C., Alcántara-Ayala, I., 2010, Susceptibility to mass movement processes in the municipality of Tlatlauquitepec, Sierra Norte de Puebla: Investigaciones Geográficas 73, 7-21.

Braam, R.R., Weiss, E.E.J., Burrough, P.A., 1987, Spatial and temporal analysis of mass movement using dendrochronology: Catena 14, 573-584.

Bräker, O., 2002, Measuring and data processing in tree-ring research - a methodological introduction: Dendrochronologia, 20, 203-216.

Brayshaw, D., Hassan, M.A., 2009, Debris flow initiation and sediment recharge in gullies: Geomorphology, 109, 122-131.

Bull, W.B., 2007, Tectonic Geomorphology of Mountains: A New Approach to
Paleoseismology: Massachusetts, EE.UU., Blackwell Publishing, 328 pp.

Capra, L., Lugo-Hubp, J., Dávila-Hernández, N., 2003a, Fenómenos de remoción en masa en el poblado de Zapotitlán de Méndez, Puebla: relación entre litología y tipo de movimiento: Revista Mexicana de Ciencias Geológicas, 20, 95-106.

Capra, L., Lugo-Hubp, J., Borselli, L., 2003b, Mass movements in tropical volcanic terrains: the case of Teziutlán (México): Engineering Geology, 69, 359-379.

Capra, L., Lugo-Hubp, J., Zamorano-Orózco, J.J., 2006, La importancia de la geología en el estudio de los procesos de remoción en masa: el caso de Totomoxtla, Sierra Norte de Puebla, México: Boletín de la Sociedad Geológica Mexicana, 2, 205-214.

Cerano-Paredes, J., Molina-Pérez, I., Esquivel-Arriaga, G., Cervantes-Martínez, R., Villanueva-Díaz, J., Franco-Ramos, O., Méndez-González, J., CambrònSandoval, V.H., Cardoza-Martínez, G.F., 2019, Dendroecological study of Juniperus deppena Steud, en Pompa-García, M., Camarero, J. (eds.), Latin American Dendroecology, Combining Tree-Ring Sciences and Ecology in a Megadiverse Territory: Switzerland, Sringer, 203-223.

Clague, J.J., 2013, Landslide en Bobrowsky, P.T. (ed), Encyclopediaof Natural Hazards:London,Springer, 594-602.

Clerici, A., Perego, S., Tellini, C., Vescovi, P., 2002, A procedure for landslidesusceptibility zonation by the conditional analysis method: Geomorphology 48, 349-364.

Comisión Nacional del Agua (CNA), 2014, Climatic Computer Program, [https://www.gob.mx/conagua] [CD].

Cook, E.R., 1985, A time-series analysis approach to tree-ring standarization: Arizona, EE.UU., University of Arizona, Tesis Doctoral, 171 pp.

Copenheaver, C, A., Pokorski, E.A., Currie, J.E., Abrams, M.D., 2006, Causationof false ring formation in Pinusbanksiana: A comparisonofage, canopyclass, climate and growthrate:Forest Ecology and Management 236, 348-355.

Costanzo, S., di Massa, G., Costanzo, A., Morrone, L., Raffo, A., Spadafora, F., Borgia, A., Formetta, G., Capparelli, G., Versace, P., 2015, Low-Cost Radars Integrated into a Landslide Early Warning System, en Rocha A., Correia, A.M., Costanzo, S., Reis, L.P (eds), New Contributions in Information Systems and Technologies: Poland, Springer, 11-19.

Cuéllar-Cárdenas, M.A., Nieto-Samaniego, A.F., Levresse, G., Alaniz-Alvarez, S.A., Solari, L., Ortega-Obregón, C., López-Martínez, M., 2012, Límites temporalis de la deformación por acortamiento Laramide en el centro de México: Revista Mexicana de Ciencias Geológicas 29, 179-203.

De Bouchard d'Aubeterre, G., Favillier., R, Mainieri, A., Lopez-Saez, J., Eckert, N., Saulnier, M., Peiry, J.L., Stoffel, M., Corona, C., 2019, Tree-ring reconstruction of snowavalanche activity: Does avalanche path selection matter?: Science of the Total Environment 684, 496-508.

Deng, X., Zhang, Q.B, 2015, Tree growth and climate sensitivity in open and closed forest of the southeastern Tibetan Plateau: Dendrochronologia,33, 25-30.

Derose, R.J., Bekker, M.F., Jelgren, R.K., Buckley, B.M., Speer, J.H., Allen, E.B., 2016, Dendrochronology of Utah Juniper (Juniperus Osteosperma (Torr.) little): Tree-Ring Research, 72, 1-14.

Eguiluz de Antuñano, S., Aranda-García, M., Marrett, R., 2000, Tectónica de la Sierra Madre Oriental, México: Boletín de la Sociedad Geológica Mexicana, 53, 1-26.

Favillier, A., Saez, J.L., Corona, C., Trappmann, D., Toe, D., Stoffel, M., Rovéra, G., Berger, F., 2015, Potential of two submontane brad leaved species (Acer opalus, Quercus pubescens) to reveal spatio temporal patterns of rock fall activity: Geomorphology, 246, 35-47.

Feizizadeh, B., Blaschke, T., Tiede, D., Moghaddam, M.H.R., 2017, Evaluating fuzzy operators of an object-based image analysis for detecting landslides and their changes: Geomorphology, 293, 240-254.

Franco-Ramos, O., Stoffel, M., Vázquez-Selem, L., Capra, L., 2013, Spatiotemporal reconstruction of lahars on the southern slopes of Colima Volcano, México - A dendrogeomorphic approach: Journal of Volcanology and Geothermal Research, 267, 30-38.

Franco-Ramos, O., Stoffel, M., Vázquez-Selem, L., 2016a, Tree-ring based record of intra-eruptive lahar activity: Axaltzintle Valley, Malinche Volcano, México: Geochronometría, 43, 74-83.

Franco-Ramos, O., Castillo, M., Muñoz-Salinas, E., 2016b, Using tree-ring analysis to evaluate intra-eruptive lahar activity in the Nexpayantla 
Gorge, Popocatépetl volcano (central Mexico): Catena, 147, 205-215.

Franco-Ramos, O., Vázquez-Selem, L., Zamorano-Orozco, J.J., VillanuevaDíaz, J., 2017, Edad, dinámica geomorfológica y tipología de barrancas en el sector norte del volcán Popocatépetl, México: Boletín de la Sociedad Geológica Mexicana, 69(1), 1-19.

Franco-Ramos, O., Vázquez-Selem, L., Stoffel, M., Cerano, J., Villanueva, J., 2019a, Tree-rings based analysis of the 2001 pyroclastic flow and posteruptive tree colonization on Popocatépetl volcano, Mexico:Catena,179, 149-159.

Franco-Ramos, O., Stoffel, M., Ballesteros-Cánovas J. A., 2019b, Reconstruction of debris-flow activity in a temperate mountain forest catchment of central Mexico: Journal of Mountains Science, 16(9), 2096-2109.

Franco-Ramos, O., Ballesteros-Cánovas, J.A., Figueroa-García, J.E., VázquezSelem, L., Stoffel, M., Caballero, L., 2020, Modelling the 2012 Lahar in a Sector Jamapa George (Pico de Orizaba Volcano, Mexico) Using RAMMS and Tree-Ring Evidence: Water, 12, 1-15.

Fritts, H.C., 1976, Tree Rings and Climate: Arizona, EE.UU. University of Arizona, Academic Press, 571 pp.

Guzzetti, F., Reichenbach, P., Cardinali, M., Ardizzone, F., Galli, M., 2003, The impact of landslides in the Umbria region, central Italy: Natural Hazards and Earth System Sciences 3, 469-486.

Holmes, R.L., 1983. Computer-assisted quality control in tree-ring dating and measurement, Tree Ring Bulletin, 43, 69-78.

Jakob, M., Hungr, O., 2005 (eds.), Debris - flow Hazards and Related Phenomena: Chichester, U.K., Springer, 795 pp.

INEGI (Instituto Nacional de Estadística y Geografía), 1998, Carta topográfica E14B24 (Mexcaltepec) Escala 1: 50,000: Ciudad de México, México, Instituto Nacional de Estadística y Geografía, 1 mapa.

INEGI (Instituto Nacional de Estadística y Geografía), 2013, Guía para la interpretación de cartografía. Uso del suelo y vegetación: Ciudad de México, México, Instituto Nacional de Estadística y Geografía, 1-200.

Ismail-Zadeh, A., Cutter, S. (eds.), 2015, Disaster Risks Research and Assessment to Promote Risk Reduction and Management: Paris, International Council of Science (ICSU) - International Social Science Council (ISSC), $47 \mathrm{pp}$.

Larsen, I.J., Pederson, J.L., Schmidt, J.C., 2006, Geologic versus wildfire control son hillslope processes and debris Flow initiation in the Green River canyons of Dinosaur National Monument: Geomorphology, 81, 114-127.

Lopez-Saez, J., Corona, C., Stoffel, M., Berger, F., 2013, High-resolution fingerprints of past landsliding and spatially explicit, probabilistic assessment of future reactivations: Aiguettes landslide, Southeastern French Alps: Tectonophysics, 602, 355-369.

Lugo-Hubp, J., 1990, El Relieve de la República Mexicana: Revista Mexicana de Ciencias Geológicas, 9(1), 82-111.

Lugo-Hubp, J., Zamorano-Orozco, J.J., Capra, L., Inbar, M., AlcántaraAyala, I., 2005, Los procesos de remoción en masa en la Sierra Norte de Puebla, octubre de 1999: Causa y efectos: Revista Mexicana de Ciencias Geológicas,22(2), 212-228.

Magre, J, M., Ivars, T.V., López, B.C., Salicrup, D.P., Zaragoza, R.M., Mateo, S.S., Junca, M.B., 2015, Análisis dendroclimático de Pinuspseudostrobus y Pinus devoniana en los municipios de Áporo y Zitácuaro (Michoacán), Reserva de la Biósfera de la Mariposa Monarca: Universidad Nacional Autónoma de México, Investigaciones Geográficas, 88, 19-32.

Mainieri R., López-Saez, J., Corona, C., Stoffel, M., Bourrier, F., Eckert, N., 2019, Assessment of the recurrence intervals of rockfall through dendrogeomorphology and counting scar approach: A comparative study in a mixed forest stand from the Vercors massif (French Alps): Geomorphology, 340, 160-171.

Molina-Pérez, I.M., 2018, Reconstrucción histórica de la precipitación para Bocoyna, Chihuahua a través de anillos de crecimiento de Juniperus deppeana (Steud.) y Pseudotsugamenziesii (Mirb. Franco): Durango, México, Universidad Autónoma de Chapingo, Tesis de Maestría, 78 pp.

Morino C., Conway, S.J., Balme, M.R., Hillier, J., Jordan, C., Saemundsson, P., Argles, T., 2018, Debris-flow reléase processes investigated through the análisis of multitemporal LiDAR in the north-western Iceland: Earth Surface Processes and Landforms, 44, 144-159.
Murillo-García, F.G., Alcántara-Ayala, I., 2017, Landslide inventory map of the municipality of Teziutlán, Puebla, México (1942-2015): Journal of Maps, 13, 767-776.

Murillo-García, F.G., Alcántara-Ayala, I., Ardizzone, F., Cardinalli, M., Fiourucci, F., Guzzetti, F., 2015, Satellite stereoscopic-pair images of very high resolution: a step forward for the development of landslide inventories: Landslides, 12, 277-291, DOI: 10.1007/s10346-014-0473-1

Paolini, L., Villalba, R., Grau, H.R., 2005, Precipitation variability and landslide occurrence in a subtropical mountain ecosystem of NW Argentina: Dendrochronologia, 22, 175-180.

Phipps, R.L., 1985, Collecting, preparing, crossdating, and measuring tree increment cores: United States Geological Survey, 1-55.

Rinn, F., 2003, TSAP-Win. Time Series Analysis and Presentation for Dendrochronology and Related Applications. Version 4.64 for Microsoft Windows. User Reference: Rinntech, Heidelberg, Germany 22 pp., disponible en <http://www.rinntech.de>, consulta: 6 de diciembre de 2019.

Rozas, V., Olano, J.M., 2013, Environmental heterogeneity and neighbourhood interference modulate the individual response of Juniperusthurifera treering growth to climate: Dendrochronologia, 31, 105-113.

Scheffers, A.M., May, S.M., Kelletat, D.H., 2015, Landforms of the World with Google Earth. Understanding our environment:Dordrecht, Heidelberg, New York, London,Springer, $391 \mathrm{pp}$.

SGM (Servicio Geológico Mexicano), 2012, Carta Geológico-Minera Mexcaltepec E14B24, escala 1:50,000: Hidalgo, México, Servicio Geológico Mexicano, 1 mapa.

Shroder Jr, J.F., 1980, Dendrogeomorphology: Review and new techniques of tree-ring dating: Progress in Physical Geography, 4, 161-188.

Šilhán, K., 2019, Tree-ring eccentricity in the dendrogeomorphic analysis of landslides - A comparative study: Catena,174, 1-10.

Speer, J.H., 2010, Fundamentals of Tree-Ring Research: Arizona, U.S.A., University of Arizona, $360 \mathrm{pp}$.

Spond, M.D., Van de Gevel, S.L., Grissino-Mayer, H.D., 2014, Climate-growth relationships for Rocky Mountain juniper (juniperuss copulorum Sarg.) on the volcanic badlands of western New Mexico, USA: Dendrochronologia, 32, 137-143.

Stoffel, M., Bollschweiler, M., 2008, Tree-ring analysis in natural hazards research - an overview: Natural Hazards and Earth System Sciences, 8, 187-202.

Stoffel, M., Bollschweiler, M., 2009, What Tree Rings Can Tell About EarthSurface Processes: Teaching the Principles of Dendrogeomorphology: Geography Compass, 3, 1013-1037.

Stoffel, M., Corona, C., 2014, Dendroecological dating of geomorphic disturbance in tres: Tree-Ring Research, 70, 3-20.

Stoffel, M., Schneuwly, D., Bollschweiler, M., Liévre, I., Delaloye, R., Myint, M., Monbaron, M., 2005, Analyzing rockfall activity (1600 - 2002) in a protection forest - a case study using dendrogeomorphology: Geomorphology, 68, 224-241.

Stoffel, M., Bollschweiler, M., Vázquez-Selem, L., Franco-Ramos, O., Palacios, D., 2011, Dendrogeomorphic dating of rockfalls on low-latitude, highelevation slopes: Rodadero, Iztaccíhuatl volcano, Mexico: Earth Surface Processes and Landforms, 36, 1209-1217.

Stokes, M.A., Smiley, T.L., 1968, An Introduction to tree-ring dating: Arizona, EE.UU., University of Arizona Press, 73 pp.

Takahashi, T., 2014, Mechanics, Prediction and Countermeasures: Florida, EE.UU., CRC Press, Taylor \& Francis Group, 563 pp.

Timilsina, M., Bhandary, N.P., Dahal, R.K., Yatabe, R., 2014, Distribution probability of large-scale landslides in central Nepal: Geomorphology, 226, 236-248.

Villanueva-Díaz, J., Vázquez-Selem, L., Gómez-Guerrero, A., CeranoParedes, J., Aguirre-Gonzáles, N.A., Franco-Ramos, O., 2016, Potencial dendrocronológico de Juniperus monticola Martínez en el Monte Tláloc, México: Revista Fitotecnia Mexicana, 39(2), 175-185.

Manuscrito recibido: noviembre 15, 2019

Manuscrito corregido recibido: marzo 16, 2020

Manuscrito aceptado: marzo 16, 2020 